\title{
SEAWATER INTRUSION AND NITRATE POLLUTION IN COASTAL AQUIFER OF MARATHON BASIN
}

\author{
Papazotos P., Koumantakis I. and Vasileiou E.
}

National Technical University of Athens, School of Mining \& Metallurgical Engineering, Heroon Polytechniou Str. 9, Zographou,15780,Athens, Greece, papazotos@metal.ntua.gr, koumantakisioa nnis@gmail.com,elvas@metal.ntua.gr

\begin{abstract}
The overexploitation of groundwater and groundwater salinization cause quantitative and qualitative degradation of the water resources. The objectives of this research are to identify and investigate the extent of seawater intrusion and nitrate pollution into the coastal plain of Marathon in Eastern Attica, Greece. In the frame of this, 25 groundwater samples were collected in October 2014 from the study area and analyzed regarding the main parameters that indicated salinization of the aquifers. Specifically, water chemical analyses were carried out and statistical analyses regarding spatial distribution were performed. The results demonstrated increased values of the parameters which can be associated with seawater intrusion. Considering and evaluating the results from the chemical analyses it is obvious that seawater intrusion takes place in the area. Furthermore, the average concentration of $\mathrm{NO}_{3}^{-}$was $44.16 \mathrm{mg} \mathrm{L}^{-1}$ and this can be attributed to overexploitation of coastal aquifer for agricultural activities.
\end{abstract}

Key words: Hydrochemistry, Hydrogeology, Pollution, Groundwater.

\section{Пєрí $\lambda \psi \eta$}

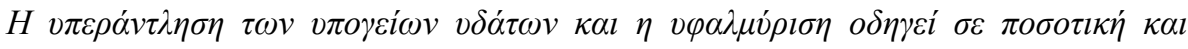

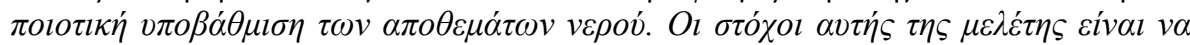

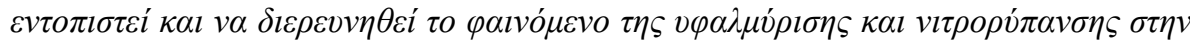

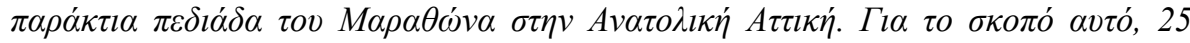

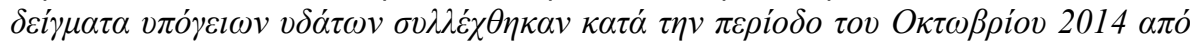

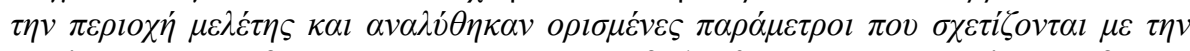

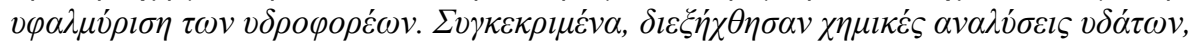

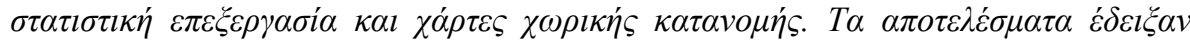

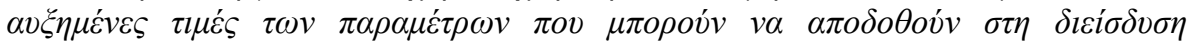

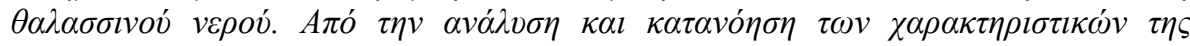

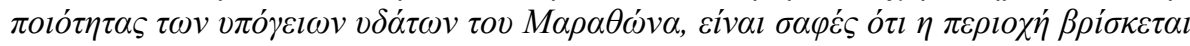

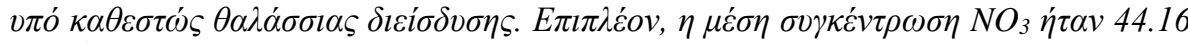

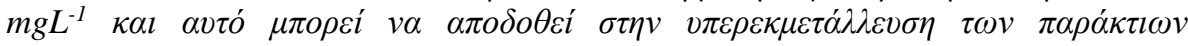

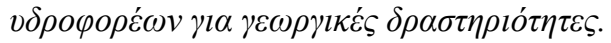

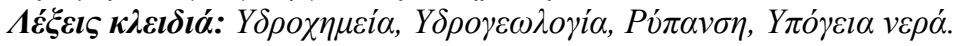




\section{Introduction}

Water management of coastal aquifers is one of the major challenges of the modern world, because it is inextricably linked to the economy of the coastal areas. The phenomenon of seawater intrusion constitutes a special case of salinization which affects the quality of coastal aquifers. Almost all the cases of seawater intrusion that are recorded were caused by human activities and especially by the intense over pumpingin coastal areas. The overexploitation of groundwater results in the quantitative and qualitative degradation of the water reservoirs.

This study investigates the phenomenon of seawater intrusion into the coastal plain of Marathon, Eastern Attica, Greece. The research area shows great interest because it is a typical case of intense human intervention. It is located in the Northeastern part of the province of Attica and is bordered to the North by the mountainous regions of Kotroni, Strati and Terokorfi, to the West by Mountain Penteli, to the East by the mountainous regions of Drakonera and Mytikas, and to the Southeast by the Kynosoura peninsula (Figure 1).

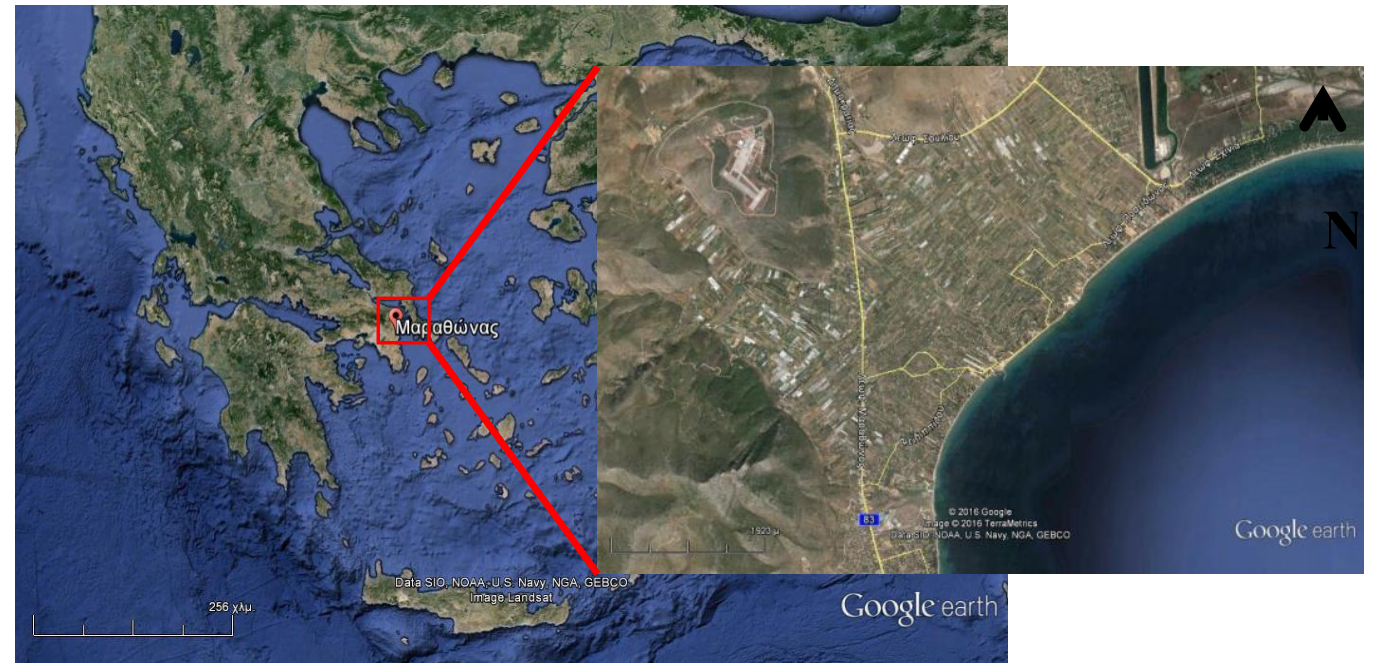

Figure 1- Location of the study area.

\section{Materials and Methods}

\subsection{Geology - Hydrogeology}

In Eastern Attica, and more specifically, in the wider Marathon area, there are four different geological units (Pavlopoulos et al., 2002). These are (from the lowest to the highest):

$\checkmark$ Almyropotamos unit that constitutes the indigenous unit of the area,

$\checkmark \quad$ Unit of Recent Greek Tectonic Cover.

$\checkmark \quad$ Unit of Afidnon - Tourkovounia.

$\checkmark$ Unit of Mavrinoras - Katsimidiou. Regarding the Lithology, the area is consisted by marbles, schists, quaternary and Neogene deposits. The marbles cover almost all the hilly and mountainous area and the quaternary sediments cover most of the growth in the plain of Marathon.

In the area of interest, two types of aquifers are developed, the karstic and alluvial aquifers. In carbonate formations, the flow of groundwater is through karst pipes and cracks and is always controlled by impermeable schists occurrences, that interfere in the entire carbon mass. In recent deposits, a circulation of the groundwater via the porous grains is observed, where the stratigraphic structure allows. The schists, mainly, and Neogene marl deposits are practically impervious 
formations. The presence of schists controls the groundwater flow in carbonate formations and thus they are creating either partially, or completely isolated carbon units, or in combination with faults, new routes of karstic water.

The karstic aquifers in marble unit of Almyropotamos may be linked to the aquifer of the lower marble of Penteli. The marbles of Almyropotamos unit are showing intense karstification. The aquifer is located far from the sea. Also, it is possibly due to the interference of schist intercalations in marbles the development of some local individual water storage, but the main discharge of the karst system is through the Makaria spring of Kato Souli.

\subsection{Meteorological Data}

The climate of Marathon basin is typically semi-dry Mediterranean. Mostly, rainfall is observed during the cold season, as in the summer there are many drought periods. Meteorological data from the water supply company (Athens Water Supply and Sewerage Company -EYDAP S.A.) was evaluated from the nearest station in the study area: Marathon (in the period 1986-1997). The average annual rainfall was estimated at about $588.9 \mathrm{~mm}$. During the period from June to September, the average monthly rainfall is lower than $20 \mathrm{~mm}$ per month resulting in negligible natural recharge of the aquifers. The average annual temperature is $17.4^{\circ} \mathrm{C}$. Figure 2 shows the temperature - precipitation diagram resulting from a combination of precipitation and temperature data. From this diagram, it seems that the wet season starts from mid-October and ends mid-March, while the dry season starts from mid-March and ends in mid October. The temperature - precipitation diagram confirms the dry climate of the region with relatively low rainfall and high temperatures during the dry season.

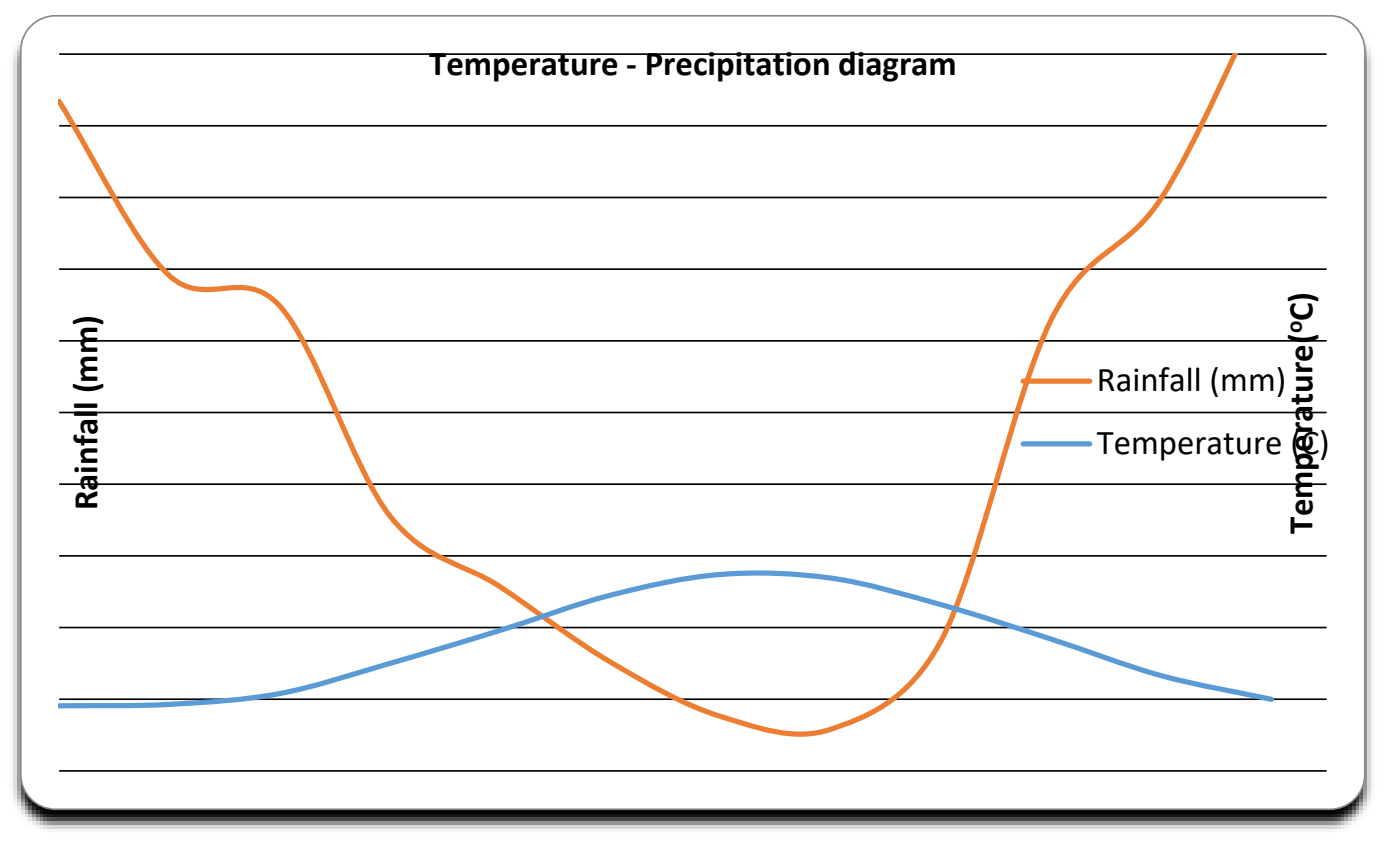

Figure 2 - Temperature - Precipitation diagram from Marathon station (in period 1986-1997).

\subsection{Sampling and Analysis}

Sampling of groundwater was carried out in October of 2014. This is the last month of the dry season, as the natural recharge is decreased. During the summer season, groundwater pumping for agricultural and potable uses is intense, so the water table is expected to be lower. Sampling sites were selected based on anthropogenic activities, in plain of Marathon.

Two water samples were taken from each site or well. One sample was used for the analyses of major anions and cations. This sample was stored in a vial polyethylene, which was flushed first 
with deionized water, and this was rinsed several times with the water sample, it was preserved in a cool, dark place, until it was transferred to the laboratory. The second sample was related to in situ measurements of unstable physicochemical parameters of water, as electrical conductivity measurements (EC), $\mathrm{pH}$ and temperature. These measurements were done with the portable instruments of the Laboratory of Engineering Geology and Hydrogeology, School of Mining Engineering - Metallurgy of the National Technical University of Athens. Totally 25 samples were collected in winter time.

\section{Results and Discussions}

\subsection{Composition of major ions}

The descriptive statistics of various chemical constituents and the ionic ratios for the 25 samples are presented in table 1. As shown in the table, all samples have values of EC> $1000 \mu \mathrm{S} \mathrm{cm}^{-1}$, which means that all measurements are over the limits of fresh water in accordance with Directive the European Union. The seawater intrusion is also indicated by the high concentrations of $\mathrm{Cl}^{-}$and $\mathrm{Na}^{+}$. Specifically, the average concentrations of $\mathrm{Cl}^{-}$were $>500 \mathrm{mg} \mathrm{L}^{-1}$ when the usual values are $<10 \mathrm{mg}$ $\mathrm{L}^{-1}$ in wet areas and $<100 \mathrm{mg} \mathrm{L}^{-1}$ in dry areas (Kallergis, 2000) and the average concentrations of $\mathrm{Na}^{+}$were $>200 \mathrm{mg} \mathrm{L}^{-1}$ when the usual values are $<20 \mathrm{mg} \mathrm{L}^{-1}$. The nitrate concentrations are also considered high and over the acceptable limits of $50 \mathrm{mg} \mathrm{L}^{-1}$. The spatial distribution of nitrates is higher in the areas that agricultural activities are taken place. Finally, ionic ratios $\mathrm{Na} / \mathrm{Cl}$ and $\mathrm{BEX}$ (Base Exchange Index) confirm the seawater intrusion regime in the Marathon Basin. Specifically, all values of the ratio $\mathrm{Na} / \mathrm{Cl}$ are $<0,876$ indicating salinization in the aquifer. BEX is proposed by Stuyfzand $(1986,2008)$ and is given by the formula:

$$
\mathrm{BEX}=\left(\mathrm{Na}^{+}+\mathrm{K}^{+}+\mathrm{Mg}^{2+}\right)-1.0716 \times \mathrm{Cl}^{-}\left(\text {all in meq } \mathrm{L}^{-1}\right)
$$

When the index value is positive, it indicates recharge process and when it is negative, it indicates salinization conditions. Almost all values are negative. Koumantakis et al. (1993), Melissaris and Stavropoulos (1999) and Fotopoulos (2004) have confirmed the seawater intrusion inthe study area. Specifically, the average values of all parameters are higher in the period of October 2003 (Table 1), according to the study of Fotopoulos (2004). The elements which are associated with seawater intrusion $\left(\mathrm{EC}, \mathrm{Cl}^{-}, \mathrm{Na}^{+}\right)$show a slight decrease in their concentration, while the nitrate pollution has decreased considerably. As shown, the qualitative situation of coastal aquifer in Marathon basin has improved in recent years.

The correlation coefficient of the studied parameters is shown in Table 2. A significant correlation is observed between $\mathrm{EC}$ and $\mathrm{Cl}^{-}(0.942)$ and between $\mathrm{Na}^{+}$and $\mathrm{Cl}^{-}(0.956)$, due to seawater intrusion. There are strong correlation between $\mathrm{EC}-\mathrm{Cl}^{-}$and $\mathrm{Na}^{+}-\mathrm{Cl}^{-}$as it is shown in the Figure 3. From the data obtained, concentration of calcium ions is much lower compared to chloride ions which can be an indication of calcium removal as a result of calcite precipitation. Precipitation takes place during the cation exchange process which is the later effect from the seawater intrusion into the aquifer: $\mathrm{Ca}^{2+}$ in the aquifer matrix is exchanged with $\mathrm{Na}^{+}$, the water becomes supersaturated with respect to calcite. The good correlation between $\mathrm{Ca}^{2+}$ and $\mathrm{Mg}^{2+}(0.926)$ is attributed to geogenic association and to the dissolution of calcite and dolomite. The main inputs of $\mathrm{SO}_{4}^{2-}$ and also $\mathrm{NO}_{3}$ - into groundwater are derived from anthropogenic activities. 
Table 1 - Descriptive statistics of samplings in the period of October $2014\left(\mathrm{EC} \mathrm{in} \mu \mathrm{Scm}^{-1}, \mathrm{Cl}^{\text {, }}\right.$ $\mathrm{NO}_{3}{ }^{-} \mathrm{Na}^{+}, \mathrm{Ca}^{+2}, \mathrm{Mg}^{+2}, \mathrm{HCO}_{3}{ }^{-}, \mathrm{SO}_{4}^{-2} \mathrm{inmgL}^{-1}$ and ionic ratios of $\mathrm{Na} / \mathrm{Cl}$ and $\mathrm{BEX}$ are unitless).

\begin{tabular}{|c|c|c|c|c|c|c|c|c|c|c|}
\hline \multirow[t]{2}{*}{ Parameter } & \multicolumn{10}{|c|}{ October 2014 (25 samples) } \\
\hline & EC & $\mathrm{Cl}^{-}$ & $\mathrm{NO}_{3}^{-}$ & $\mathrm{Na}^{+}$ & $\mathrm{Ca}^{+2}$ & $\underset{2}{\mathbf{M g}^{+}}$ & $\begin{array}{c}\mathrm{HCO} \\
3^{-}\end{array}$ & $\mathrm{SO}_{4}^{-2}$ & $\begin{array}{c}\mathrm{Na} / \\
\mathrm{Cl}\end{array}$ & $\begin{array}{c}\mathbf{B E} \\
\mathbf{X}\end{array}$ \\
\hline \multirow{3}{*}{ Mean } & 2558.9 & 508.5 & & & 202.3 & & 309.5 & 146.3 & & - \\
\hline & 2 & 6 & 44.16 & 214 & 6 & 34.2 & 4 & 2 & 0.63 & 3.08 \\
\hline & 1067.1 & 325.2 & & 147,5 & & 17.3 & 185.3 & & & \\
\hline Stdev $^{1}$ & 6 & 3 & 45.17 & 5 & 90.48 & 1 & 5 & 88.14 & 0.14 & 3.01 \\
\hline Max & 4720 & 1220 & 175 & 494 & 382 & 69 & 763 & 340 & 0.84 & 0.36 \\
\hline & & & & & & & & & & $\begin{array}{c}- \\
12.8\end{array}$ \\
\hline Min & 1025 & 75 & 4 & 38 & 102 & 11 & $\begin{array}{c}67 \\
204,7\end{array}$ & 41 & 0,33 & 9 \\
\hline Quartile 1 & 1675 & 265 & 17 & 113 & 132 & 20 & 5 & 59 & 0.55 & -4.2 \\
\hline Median & 2380 & 380 & 24 & 144 & 171 & 32 & 265,5 & 155 & 0.7 & -2.6 \\
\hline Quartile 3 & 3340 & 725 & 52 & 355 & 273 & 42 & $\begin{array}{c}413,2 \\
5\end{array}$ & 208 & 0.74 & $\begin{array}{c}- \\
1.18\end{array}$ \\
\hline Skewness & 0.39 & 0.72 & 172 & 0.5 & 0.84 & 061 & 1.05 & 0.39 & -0.59 & $1 \overline{84}$ \\
\hline Kurtosis & 2.11 & 2.49 & 5.3 & 1.71 & 2.37 & 2.2 & 3.56 & 1.99 & 2.29 & 7.32 \\
\hline October & & & & & & & & & & \\
\hline 2003(Mea & 2972.1 & 699.6 & 140.5 & 425.6 & 256.7 & 54.7 & 318.6 & 167.3 & & \\
\hline n) $)^{2}$ & 1 & 1 & 9 & 1 & 5 & 6 & 4 & 9 & - & - \\
\hline
\end{tabular}

${ }^{1}$ Standard deviation

${ }^{2}$ Fotopoulos (2004)

Table 2- Correlation matrix for all data.

\begin{tabular}{ccccccccc}
\hline & $\mathbf{E C}$ & $\mathrm{Cl}^{-}$ & $\mathrm{NO}_{3}^{-}$ & $\mathbf{N a}^{+}$ & $\mathrm{Ca}^{+2}$ & $\mathbf{M g}^{+2}$ & $\mathrm{HCO}_{3}{ }^{-}$ & $\mathbf{S O}_{4}^{-2}$ \\
\hline $\mathbf{E C}$ & 1 & & & & & & & \\
$\mathbf{C l}^{-}$ & $\mathbf{0 . 9 4 2}$ & 1 & & & & & & \\
$\mathrm{NO}_{3}{ }^{-}$ & 0.254 & -0.053 & 1 & & & & & \\
$\mathbf{N a}^{+}$ & $\mathbf{0 . 8 7 7}$ & $\mathbf{0 . 9 5 6}$ & -0.221 & 1 & & & & \\
$\mathbf{C a}^{+2}$ & $\mathbf{0 . 7 5 8}$ & 0.549 & $\mathbf{0 . 7 7 0}$ & 0.365 & 1 & & & \\
$\mathbf{M g}^{+2}$ & $\mathbf{0 . 8 6 7}$ & 0.711 & 0.626 & 0.558 & $\mathbf{0 . 9 2 6}$ & 1 & & \\
$\mathbf{H C O}_{3}^{-}$ & 0.105 & -0.209 & $\mathbf{0 . 8 9 5}$ & -0.333 & 0.668 & 0.537 & 1 & \\
$\mathbf{S O}_{4}^{-2}$ & $\mathbf{0 . 9 1 1}$ & $\mathbf{0 . 8 2 5}$ & 0.351 & $\mathbf{0 . 7 6 0}$ & $\mathbf{0 . 7 5 6}$ & $\mathbf{0 . 8 7 4}$ & 0.271 & 1 \\
\hline
\end{tabular}




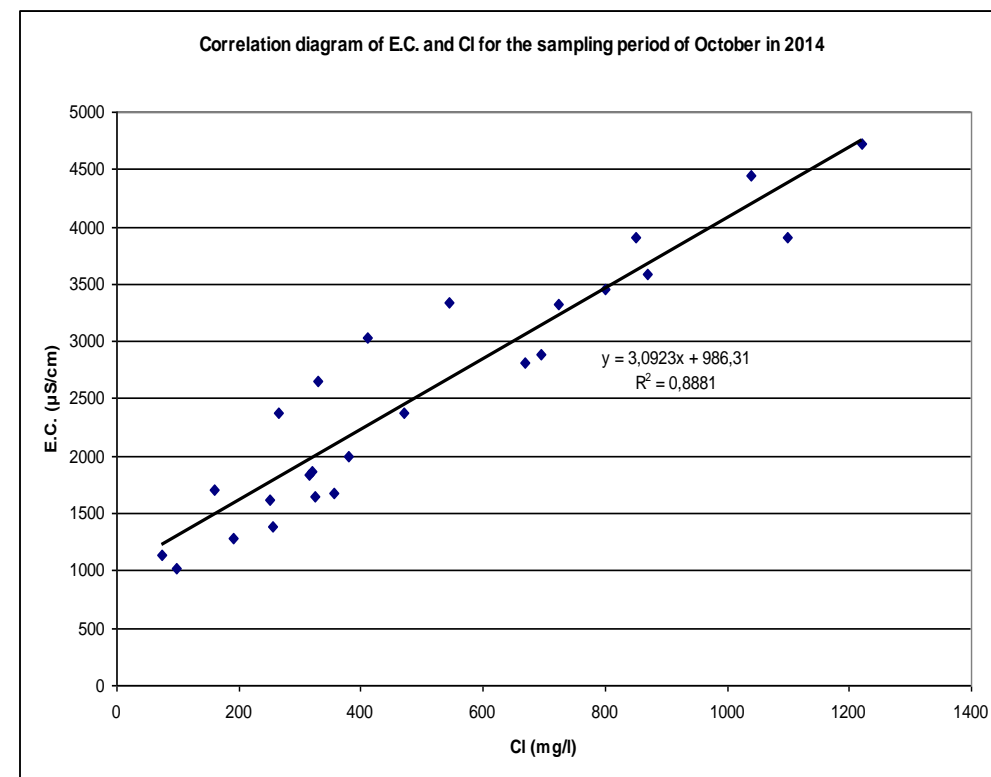

Correlation diagram of $\mathrm{Na}$ and $\mathrm{Cl}$ for the sampling period of October in 2014

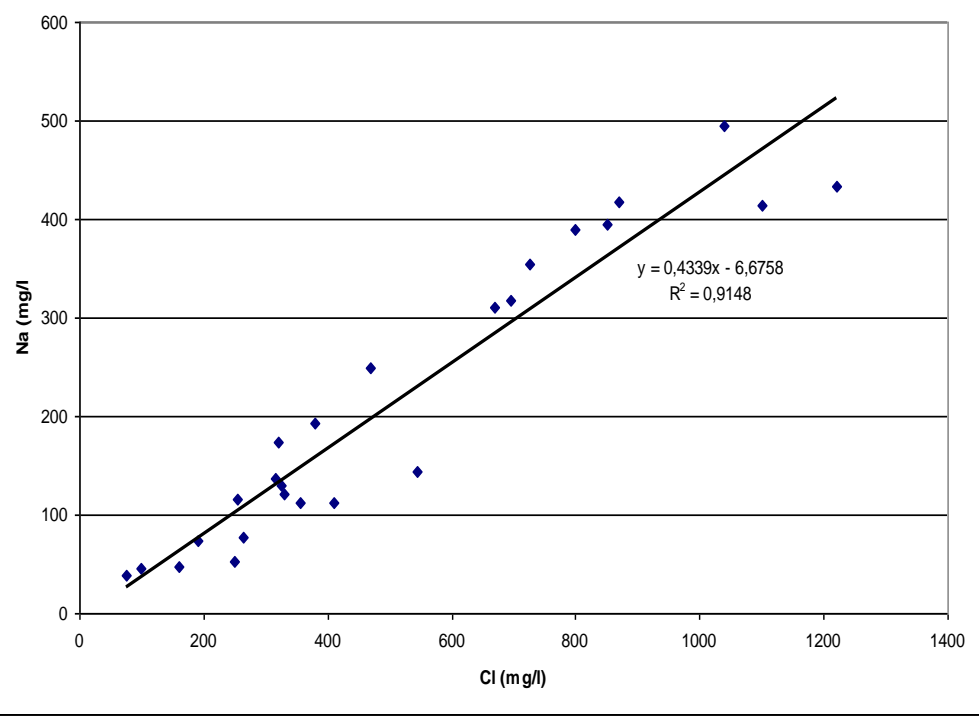

Figure 3 - Correlation diagrams of $\mathrm{EC}-\mathrm{Cl}^{-}$and $\mathrm{Na}^{+-} \mathrm{Cl}^{-}$for the sampling period of October 2014.

\subsection{Spatial Distribution}

The spatial distribution of some parameters is presented in figure 4. The statistical analysis of water sampling is shown in table 1 . As it is observed by the parameters $\mathrm{EC}, \mathrm{Cl}^{-}, \mathrm{Na}^{+}$and the ionic ratios $\mathrm{Na}^{+} / \mathrm{Cl}^{-}$and BEX (Figure 4), high values exceeding the acceptable limits, indicate seawater intrusion that are presented in the eastern part of the study area. On the west part of Marathon plain, concentrations and ionic ratios values are presented lower and it is likely to happen because the sampling locations are farther away from the coastline and on the other hand, there is possible recharge from the karstic mountain masses. The concentrations of nitrates are considered high, since they are over the indicative and the permissible limits of literature $\left(\sim 50 \mathrm{mg} \mathrm{L}^{-1}\right)$. In figure 4 (medium 
right), the spatial distribution of nitrate shows a specific point source pollution which spatially corresponds to an agricultural area. The intense agricultural activities are probably the main source of nitrate pollution in the research area.
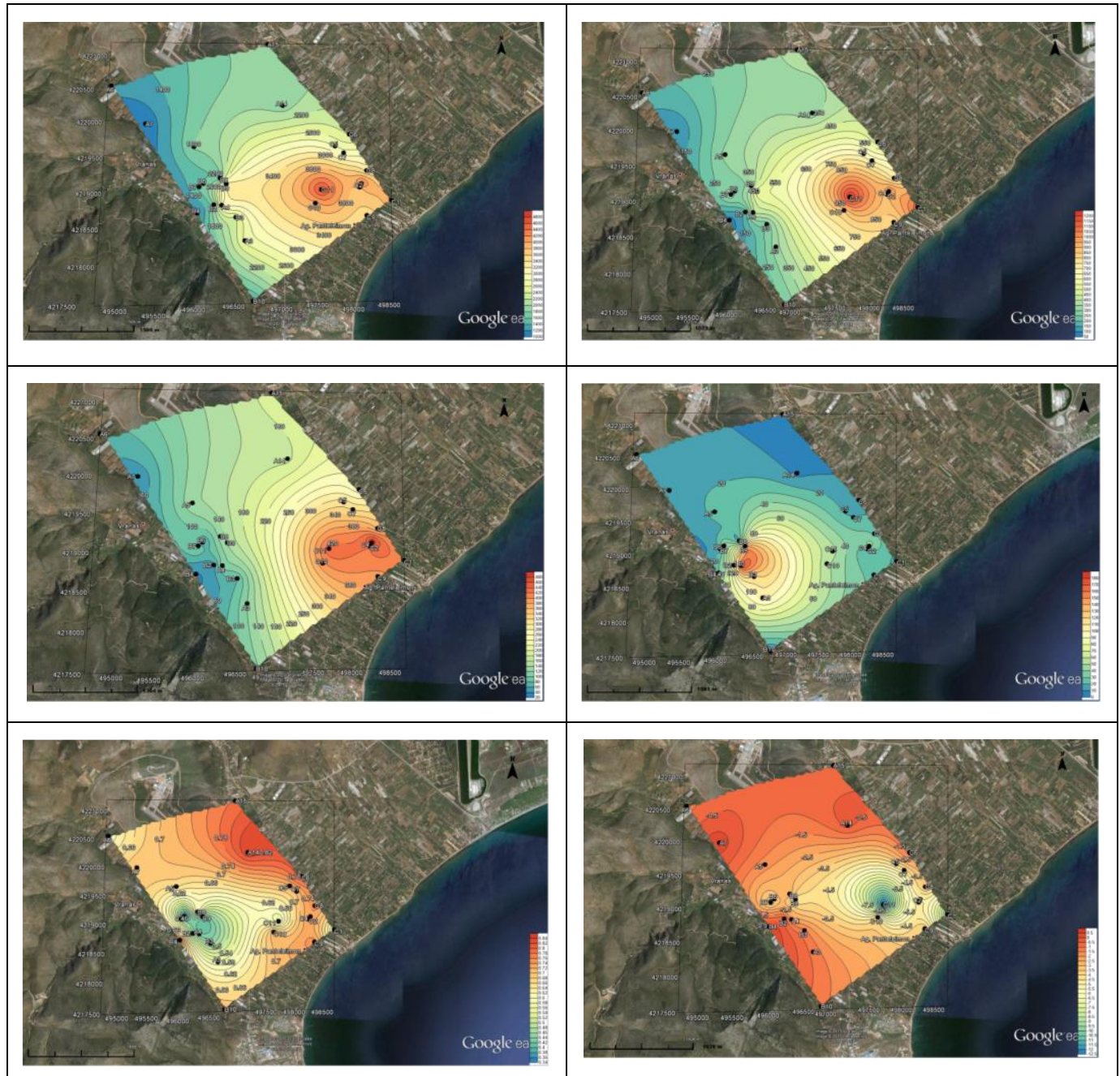

Figure 4 - Spatial distribution maps of $\mathrm{EC}$ in $\mu \mathrm{S} \mathrm{cm}^{-1}$ (upper left), $\mathrm{Cl}^{-1}$ in $\mathrm{mg} \mathrm{L}^{-1}$ (upper right), $\mathrm{Na}^{+} \mathrm{mg} \mathrm{L}^{-1}$ (medium left), $\mathrm{NO}_{3}$ in $\mathrm{mg} \mathrm{L}^{-1}$ (medium right), $\mathrm{Na} / \mathrm{Cl}$ (lower left), $\mathrm{BEX}$ (lower right)for the period of October 2014.

\subsection{Piper, Schoeller and Wilcox diagrams}

As it is shown in Piper diagram in the lowland area of Marathon, two groups of water samples are distinguished. The first group (in the blue circle in Figure 5) is characterized as $\mathrm{Ca}-\mathrm{Na}-\mathrm{Cl}-\mathrm{HCO} 3$ up to $\mathrm{Na}-\mathrm{Ca}-\mathrm{Cl}$ that definesthese samples as subsaline. The anions dominants are $\mathrm{Cl}-$, while the corresponding cations are $\mathrm{Na}+$. The second group is consisted of geoalkaline natural waters. More specifically, the water ischaracterized as acid carbonate - sulfates of formula $\mathrm{Ca}-\mathrm{HCO} 3-\mathrm{Cl}$. The anions dominants are $\mathrm{HCO} 3$, while the $\mathrm{Ca} 2+$ are in cations. The values of $\mathrm{EC}$ and chloride are very high in the coastal zone of the study area.

As it is observed in the Schoeller diagram, high concentrations of anions $\mathrm{Cl}$ - are distinguished, as seawater intrusion takes place in coastal and plain of Marathon. 


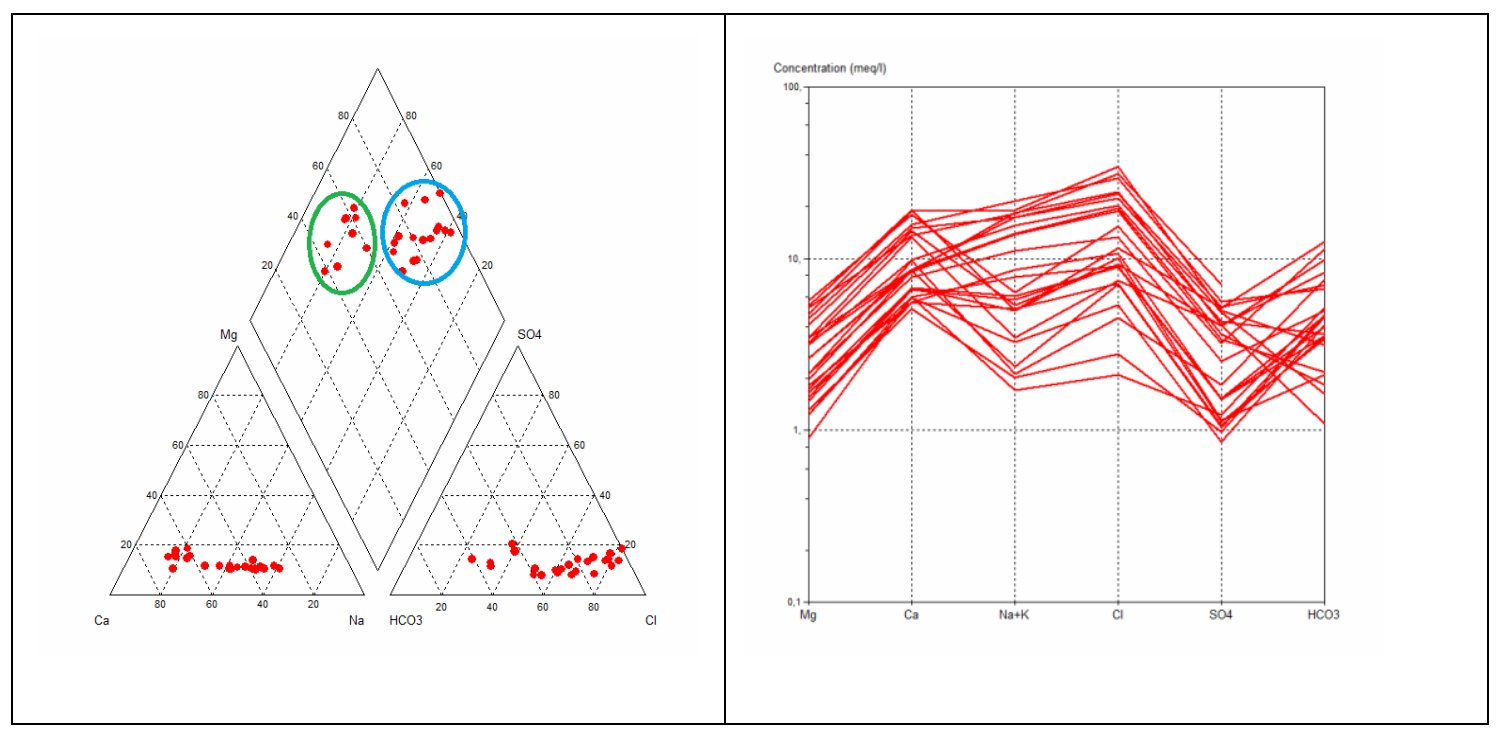

Figure 5 - Hydrochemical diagrams of Piper and Schoeller.

The United States Department of Agriculture (USDA) (1954) classifies irrigation water with respect to SAR. SAR is calculated from the following formula, all concentrations expressed in milliequivalents per litre:

$$
S A R=\frac{N a}{\sqrt{\frac{C a+M g}{2}}}
$$

The waters having SAR values less than 10 are considered excellent, 10-18 as good, 18-6 as fair, and above 26 are unsuitable for irrigation use (US Salinity Laboratory Staff, 1954) (Table 3) (Fig. 6). Wilcox (1955) diagram (Fig. 6) is widely used and is especially implemented to classify groundwater quality for irrigation (Ebraheem et al., 2012; Banoeng-Yakubo et al., 2009; Ganyaglo et al., 2011; Swarna Latha and Nageswara Rao, 2012; Mtoni et al., 2013). The calculated SAR values range from 0.86 to 7.55 in groundwater in the study area and almost all samples fall into excellent class (Table 3). The USDA (1954) has also classified irrigation waters on the basis of electrical conductivity (EC) as indicated in Table 3.

According to USSL diagram (US Salinity Laboratory Staff, 1954), which is widely used for rating the irrigation waters, water can be grouped into 16 classes. It uses SAR (vertical axis) and specific conductance (horizontal axis) (Fig. 6) (Table 4). The conductivity (horizontal axis) is classified into low (C1), medium (C2), high (C3) and very high (C4) salinity zones. These zones (C1-C4) have the value of EC $<250,250-750,750-2.250$ and $>2.250 \mu \mathrm{S} \mathrm{cm}^{-1}$, respectively. The SAR (vertical axis) is subdivided into four classes, with decreasing limiting values as EC increases: low (S1), medium (S2), high (S3) and very high (S4) sodium hazard. Significance of classes in relation to EC and SAR is presented in Table 4. The results show that $44 \%$ of all samples from the study area were graded as suitable for irrigation use, while $36 \%$ as unsuitable. $20 \%$ of samples were regarded as suitable under specific conditions. Groundwater samples classified as C3S1, C4S1 and C4S2 were the dominant classes. 


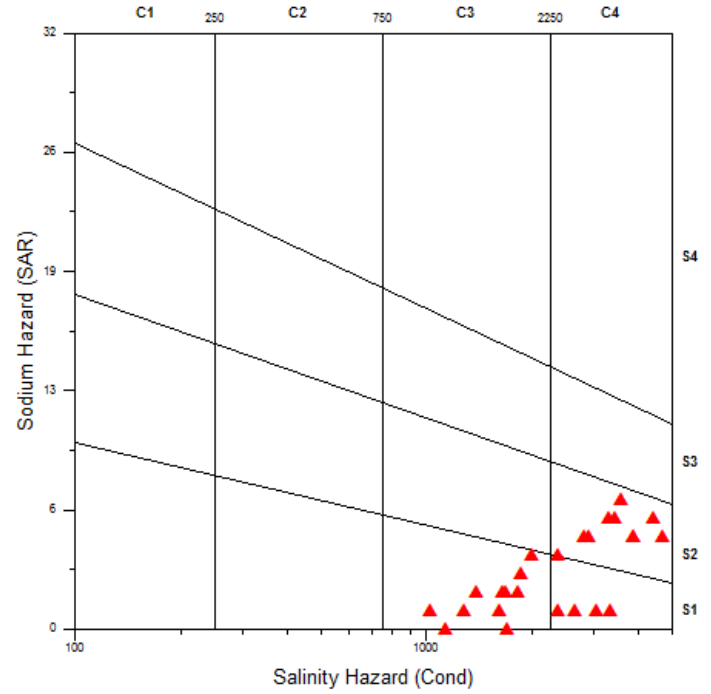

Figure 6 - Groundwater suitability for irrigation in the study area. Assessment was conducted using Wilcox (1955) diagram.

Table 3 - Classification of irrigation water according to USDA (1954).

\begin{tabular}{ccccc}
\hline Parameter & Range & Waterclass & Noof samples & \% \\
\hline & $<10$ & Excellent & 25 & 100 \\
SAR & $10-18$ & Good & 0 & 0 \\
& $18-26$ & Doubtful & 0 & 0 \\
& $>26$ & Unsuitable & 0 & 0 \\
\hline $\mathbf{E C}$ & $100-250$ & Lowsalinitywater & 0 & 0 \\
$\left(\boldsymbol{\mu S ~ c m} \mathbf{1}^{-1}\right)$ & $250-750$ & Mediumsalinitywater & 0 & 0 \\
& $750-2250$ & Highsalinitywater & 11 & 44 \\
& $>2250$ & Veryhighsalinitywater & 14 & 56 \\
\hline
\end{tabular}

Table 4 - Summary of groundwater classification based on USSL diagram.

\begin{tabular}{ccccc} 
No & Category & Noofsamples & Salinity/sodiumhazard & Statusforirrigation \\
\hline 1 & C3-S1 & 11 & $\begin{array}{c}\text { High salinity hazard - low } \\
\text { sodium hazard } \\
\text { Very high salinity hazard - }\end{array}$ & Suitable \\
2 & C4-S1 & 5 & $\begin{array}{c}\text { low sodium hazard } \\
\text { Very high salinity hazard - } \\
\text { medium sodium hazard }\end{array}$ & Suitableinspecificcondition \\
3 & C4-S2 & 9 & Unsuitable \\
\hline
\end{tabular}




\section{Conclusions}

In the basin of Marathon, Eastern Attica, Greece, a hydrogeological research carried out in the period of October 2014. The hydrogeological and hydrochemical study in Marathon basin shows that the area is under seawater intrusion regime. The qualitative characteristics of groundwater haven't changed significantly during the last decades, as it is described in previous studies (Koumantakis $e t$ al., 1993; Melissaris and Stavropoulos, 1999). Summarizing, EC expresses the total concentration of salts in the water and it is a measure of the quality of groundwater. The EC measured values range from $1025 \mu \mathrm{S} \mathrm{cm}^{-1}$ to $4720 \mu \mathrm{S} \mathrm{cm}^{-1}$. All samples show EC $>1000 \mu \mathrm{S} \mathrm{cm}^{-1}$, the minimum value is bigger than the target value of the European Union $\left(\sim 400 \mu \mathrm{S} \mathrm{cm}^{-1}\right)$. The presence of $\mathrm{Cl}^{-}$usually reveals seawater intrusion into the aquifer and is directly connected with the high values of EC. The concentrations of $\mathrm{Cl}^{-}$in the Marathon coastal plain are considered high, making explicit the qualitative degradation of the groundwater reserves in the study area. The normal $\mathrm{Na}^{+}$concentrations in groundwater are $<20 \mathrm{mg} \mathrm{L}^{-1}$. However, concentrations of $\mathrm{Na}^{+}$in the study area are ranging from $38 \mathrm{mg} \mathrm{L}^{-1}$ to $494 \mathrm{mg} \mathrm{L}^{-1}$. The increased concentration is probably due to contamination by seawater intrusion and possible ion exchange of $\mathrm{Ca}^{2+}$ and $\mathrm{Na}^{+}$because of seawater intrusion. Spatially, the sampling locations were close to the sea - in the east of the study area - showing the highest values of $\mathrm{EC}, \mathrm{Cl}^{-}$and $\mathrm{Na}^{+}$. In addition, the spatial distribution of ionic ratios $\mathrm{Na} / \mathrm{Cl}$ and $\mathrm{BEX}$ show high values in the eastern part of the study area, confirming the salination conditions.

The nitrates $\left(\mathrm{NO}_{3}{ }^{-}\right)$are derived from nitrogen compounds through complex processes such as ammonification and nitrification. These processes take place above groundwater level, especially in the soil where there are abundant organic material and oxygen. The nitrate is one of the forms of dissolved nitrogen which is highly mobile in groundwater. $\mathrm{NO}_{3}{ }^{-}$is the most prevalent contaminant and the large spread occurs due to agricultural activities such as nitrogen and nitrate fertilizers. Average value of $\mathrm{NO}_{3}{ }^{-}$was $44.16 \mathrm{mg} \mathrm{L}^{-1}$, while $36 \%$ of collected samples exceeded the maximum permitted level $\left(\sim 50 \mathrm{mg} \mathrm{L}^{-1}\right)$. The concentrations of $\mathrm{NO}_{3}{ }^{-}$are considered high, but their detection is expected in the areas where there are agricultural crops. On the spatial distribution map of $\mathrm{NO}_{3}{ }^{-}$, a large point of source pollution is presented, which corresponds to agricultural area. West of the polluted area, an abrupt qualitative change is observed, which is likely due to natural recharge from meteoric water, while at the coastal region, of the Eastern region of the map, Neogene formations containing organic material contribute to the reduction of nitrate ions concentrations.

The hydrogeochemical results show that several processes determine major ionic composition of groundwater in the study area. The distribution pattern of major ions shows compositional variation in the groundwater samples. In general, the concentration of cations decreases in the order $\mathrm{Na}^{+}>$ $\mathrm{Ca}^{2+}>\mathrm{Mg}^{+}$and of anions in the order $\mathrm{Cl}^{-}>\mathrm{HCO}_{3}{ }^{-}>\mathrm{SO}_{4}{ }^{2-}>\mathrm{NO}_{3}{ }^{-}$. However, $\mathrm{HCO}_{3}{ }^{-}$dominates over $\mathrm{Cl}^{-}$in some samples. Correlation analysis indicates that most of the ions are positively correlated. The reasonably good correlation among the ions, especially $\mathrm{Na}^{+}$and $\mathrm{Cl}^{-}$, indicates that such ions are mainly derived from the same source of saline waters. This implies that the groundwater salinization process of the study area occurs near to the coastline associated with seawater.

In conclusion, the coastal plain of Marathon lies under seawater intrusion presenting high values EC, $\mathrm{Cl}^{-}, \mathrm{Na}^{+}$and ionic ratios $\mathrm{Na} / \mathrm{Cl}$ and $\mathrm{BEX}$, as well as increased values of $\mathrm{NO}_{3}{ }^{-}$because of extensive farming activities (fertilizers, pesticides). The area is characterized from the overexploitation of the aquifers by overpumping because of irrigation land use. The salinity and sodium hazards of groundwater in Marathon basin were mainly classified as C3S1, C4S1 and C4S4, i.e., high salinity with low and medium sodium problems.

\section{References}

Banoeng-Yakubo, B., Yidana, S.M. and Nti, E., 2009.An evaluation of the genesis and suitability o f groundwater for irrigation in the Volta Region, Ghana, Environ. Geol., 57(5), 1005-1010. 
Ebraheem, A.M., Sherif, M.M., Al Mulla, M.M., Akram, S.F. and Shetty, A.V., 2012.A geoelectric al and hydrogeological study for the assessment of groundwater resources in Wadi Al Bih, UAE, Environ. Earth. Sci., 67,845-857.

Fotopoulos, N., 2004. Hydrogeological regime of Marathon plain and effects from the Olympic pro jects, Master thesis, NTUA.

Ganyaglo, S.Y., Banoeng-Yakubo, B., Osae, S., Dampare, S.B. and Fianko, J.R., 2011. Water qual ity assessment of groundwater in some rock types in parts of the eastern region of Ghana, $E$ nviron. Earth Sci., 62(5), 1055-1069.

Kallergis, G., 2000.Applied environmental hydrogeology, Volume B, (T.C.G.), Athens (in Greek).

Koumantakis, I., Georgalas, L. and Morfopoulos, Z., 1993. Qualitative degradation of Marathon plain underground waters and diversification trends, 2nd Hydrogeological Congress (in Greek).

Melissaris, P. and Stavropoulos, X., 1999. Hydrogeological assessment of Marathon plain, Attica, ministry of agriculture, Athens (in Greek).

Mtoni Y., Mjemah, I.C., Bakundukize, C., Van Camp, M., Martens, K. and Walraevens, K., 2013. Saltwater intrusion and nitrate pollution in the coastal aquifer of Dar es Salaam, Tanzania, $E$ nviron. Earth Sci., 70, 1091-1111.

Pavlopoulos, K., Karibalis, E. and Maroukian, H., 2002. Geomorphological evolution of Oinoi rive $\mathrm{r}$ basin (B. Attica) in the Quaternary, Proceedings of the 6th Panhellenic Geographical Con ference of the Greek Geographical Society (in Greek).

Stuyfzand, P.J., 1986. A new hydrochemical classification of water types: principles and applicatio $\mathrm{n}$ to the coastal dunes aquifer system of the Netherlands, Proc. 9th SaltWater Intrusion Mee ting, Delft 12-16 may, Delft Univ. Techn., 641-655.

Stuyfzand, P.J., 2008. Base Exchange Indices as Indicators of Salinization or Freshaning of (Coastal) A quifers, 20th Salt Water Intrusion Meeting, June 23-27, 2008, Naples, Florida, USA, 262-265.

Swarna Latha, P. and Nageswara Rao, K., 2012.An integrated approach to assess the quality of groun dwater in a coastal aquifer of Andhra Pradesh, India, Environ. Earth Sci., 66(8), 2143-2169.

USSalinity Laboratory Staff, 1954. Diagnosis and improvement of saline and alkali soils, USDA H andbook No.60, U.S., GPO, Washington, D.C.

Wilcox, L.V., 1955. Classification and use of irrigation waters, US Geological Department Agric C irc, 969, 19 pp. 